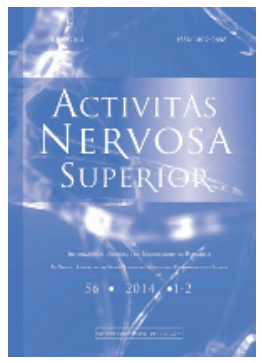

\title{
EVENT-RELATED POTENTIALS AND THEIR APPLICATIONS
}

\author{
Leos Landa ${ }^{1}$, Zdenek Krpoun ${ }^{1,2}$, Martina Kolarova ${ }^{2}$, Tomas Kasparek ${ }^{1}$ \\ ${ }_{1}^{1}$ Department of Psychology and Psychosomatics, Faculty of Medicine, Masaryk University, Brno, Czech Republic \\ ${ }^{2}$ Department of Psychology, Faculty of Arts, Masaryk University, Brno, Czech Republic
}

\begin{abstract}
Event-related potentials (ERPs) are characterised as brain voltage fluctuations associated in time with some physical or mental occurrence and represent a non-invasive technique reflecting activity of complex neuronal networks responsible for new stimuli detection and discriminative behaviour of individuals. ERPs are measured using electroencephalography and their applications became widespread since 1960s of the last century. This review brings introduction into the ERPs technique and characteristics of the individual ERPs components (particularly wave P300, Contingent Negative Variation, Mismatch Negativity and Bereitschaftspotential). In addition, it summarizes changes of ERPs associated with neurologic and psychiatric diseases and finally, it mentions possible use of this approach for purposes of experimental psychology.
\end{abstract}

Key words: Event-related Potentials; P300; Contingent Negative Variation; Mismatch Negativity; Psychiatric and Neurological Disorders

\section{INTRODUCTION}

Event-related potentials (ERPs) represent a technique that is based on measuring of electroencephalogram (EEG) signals associated with presentation of specific stimuli or impulses. This technique is able to record processes in the brain with a precision of milliseconds (Gaudreault et al., 2013). Thus, ERPs are a specialized form of EEG and may be interpreted as a subset of evoked potentials (Casey, 2010). ERPs are characterised as voltage fluctuations associated in time with some physical or mental occurrence. In other words, ERPs are very small voltages generated in the brain structures as reaction to specific stimuli (Blackwood \& Muir, 1990). They are believed to reflect activity of complex neuronal networks responsible for new stimuli detection and discriminative behaviour of individuals (e.g. important stimulus versus unimportant) (Bares, 2011). ERPs are not affected by cultural and educational influences and can bring useful, non-invasive means for the cognitive process exploration (Lai et al., 2010).

*Correspondence to: Leos Landa: landa@med.muni.cz

Received June 4, 2014; accepted July 8, 2014; Act Nerv Super 56(1-2), 17-23; ISSN-1802-9698 
ERPs can be extracted from EEG by filtering and averaging of the signal (Picton et al., 2000). The most frequent way how to extract the signal is recording of a number of EEG epochs, each time-locked to repetitions of the same event and acquiring an average waveform (Kuperberg, 2008). The electrical information occurring on the EEG originates from different points at the scalp. These points are technically termed derivations (Gesualdi \& Franca, 2011).

ERPs can be classified into two classes. The early waves (reaching the peak approximately within the first 100-200 milliseconds after stimulus) are referred to as 'sensory' or 'exogenous' because they depend largely on the physical parameters and are determined by the physical nature of the eliciting stimulus (Kuperberg, 2008). ERPs occurring later are called 'cognitive' or 'endogenous'. These ERPs are sensitive to alternations in subject's mental state reflecting meaning of the stimulus (Kuperberg, 2008; Sur \& Sinha, 2009). They examine information processing and reflect the manner in which the subject evaluates the stimulus. The waveforms can be characterized according to latency and amplitude (Sur \& Sinha, 2009).

\section{COMPONENTS OF ERPS}

Components of ERPs are classified according to their polarity (positive or negative going voltage), timing, scalp distribution, and sensitivity to task manipulations (Woodman et al., 2010). They are represented particularly by wave P300, Contingent Negative Variation and the complex of middle- and long-latency evoked potentials, Mismatch Negativity and Bereitschaftspotential (Bares, 2011).

The wave P300 has been suggested as the most prominent and most extensively studied. In general, letter ' $\mathrm{P}$ ' in abbreviations indicates positive waves, whereas letter ' $\mathrm{N}$ ' negative waves according to their polarity. Numbers indicate either the latency (in milliseconds) or the ordinal position of the component in the waveform. The wave P300 is also referred to as wave P3, the third positive wave, or the wave with 300 ms latency (Hruby \& Marsalek, 2003). The P300 wave is a positive deflection in the human ERP. It can be obtained in an "oddball" paradigm when a subject detects an occasional "target" stimulus in a regular train of standard stimuli (Picton, 1992). The P300 wave develops if the subject is actively engaged in the task of detecting the targets. The task of the experimental subject is responding to the presence of target stimulus by a given motor reaction, e.g. to button pressing (Hruby \& Marsalek, 2003). Amplitude of the wave varies with the improbability of the targets and latency with the difficulty of discriminating the target stimulus from the standard stimuli. Typical peak latency in young adult subjects making a simple discrimination is $300 \mathrm{~ms}$ (Picton, 1992). Pathological changes of the P300 wave can occur for example in individuals suffering from Alzheimer's disease and other dementias, Parkinson's disease, schizophrenia or depression (Hruby \& Marsalek, 2003).

Contingent Negative Variation (CNV) was for the first time described by Walter (1964a,b) and is characterised as a sustained potential change (involving mainly the frontal cortex) during which the surface of the brain becomes electro-negative by about $20 \mu \mathrm{V}$ with respect to remote reference electrode or deeper structures (Walter et al., 1967). It is a slow negative deviation of EEG activity on the scalp which occurs in the interval between warning stimulus (S1) and imperative stimulus (S2) that is followed by a mental or motor response. CNV is a complex endogenous potential that reflects many mental and cognitive activities and processes, such as sensation, attention, expectance, stress or discrimination (Bares, 2011). $\mathrm{CNV}$ is typically acquired as average of several EEG segments. These segments are thought as EEG record that corresponds with time period about 1.5-1 second prior to the warning stimulus and about 1-2 seconds after the imperative stimulus (Bares, 2011).

Mismatch Negativity (MMN) represents a response of the brain to violations of a rule, established by a sequence of sensory stimuli (typically in the auditory domain). It is evoked even in the absence of attention and can be used as an objective index of sound- 
discrimination accuracy and auditory sensory memory (Naatanen \& Kreegipuu, 2012). The MMN reflects the ability of the brain to perform automatic comparisons between consecutive stimuli, thus providing an electrophysiological index of sensory learning and perceptual accuracy (Garrido et al., 2009). MMN occurs when discriminable change in some repetitive aspect of auditory stimulation is present. The discriminable change can differ, e.g. frequency, duration, intensity, perceived sound-source location or silent gap instead of a tone. It has been suggested that the MMN is elicited by any violation of an acoustic regularity or pattern (Garrido et al., 2009).

Bereitschaftspotential (BP) also termed pre-motor potential or readiness potential (RP) represents an anticipatory slow wave that typically precedes a voluntary motor act. Its deficit reflects abnormal motor preparatory processes in the brain (Banerjee et al., 2014). BP comprises an early and a late part. The early part reflects the activity of supplementary motor area (SMA) as its maximum amplitude at the vertex (overlying SMA) without reference to the body parts that were involved in the movements. The late part is lateralised to the opposite hemisphere to the side of the movements and is believed to represent activity particularly of the primary motor cortices (Fumuro et al., 2013).

Other authors recognize also additional parts of an ERP trace involving P50 wave, N1 (or N100 wave), P (or P200) wave, N2 (or N200 wave), N300, N400, P600 waves, movementrelated cortical potentials or post-imperative negative variation (for more details see e.g. Sur \& Sinha, 2009).

\section{CHANGES OF ERPS IN ASSOCIATION WITH NEUROLOGIC AND PSYCHIATRIC DISORDERS}

It has been suggested that changes in event-related potentials can be associated with neurologic and psychiatric diseases (Katada et al., 2004; O'Donnell et al., 2004; Vecchio \& Maatta, 2011; Garrido-Vásquez et al., 2013). For example, patients suffering from Parkinson's disease (PD) showed a decreased early Bereitschaftspotential (Fumuro et al., 2013). Green et al. (1996) described in patients with mild PD significantly enlarged P3 amplitude despite these subjects did not show neuropsychological deficits. Thus, the authors concluded that the amplitude of $\mathrm{P} 3$ can be more sensitive for detecting subtle brain dysfunction occurring early in PD than are neuropsychological measures (Green et al., 1996). Similar finding was published by Tanaka (2000) who reported that non-demented PD patients had increased amplitude of $\mathrm{P} 3$ and N1 amplitude.

ERPs can also be used in patients with Alzheimer's disease (AD), among others for assessment of the cognitive deterioration. Lai et al. (2010) tested using ERPs probable AD patients and mild cognitive impairment patients. They found that the P300 latencies were significantly more prolonged in both probable $\mathrm{AD}$ patients and cognitive impairment patients. The authors suggested that the P300 latency can reflect cognitive decline in a very sensitive way and thus it represents a useful tool for AD severity assessment. In addition, Ally et al. (2006) suggested that P300 may identify preclinical changes in subjects with relatively high risk for the disease due to genetic predisposition. Generally, P300 is considered to be a suitable tool for evaluating of AD. It is widely accepted that P300 latency increase in elderly patients with $\mathrm{AD}$, however there is still no consensus with respect to the P300 amplitude (Pedroso et al., 2012).

Similarly, in patients with epilepsy the majority of publications reported prolonged P300 latencies and no significant reductions in P300 amplitude (Kaga et al., 2013). Another typical finding is represented by changes of Mismatch Negativity (MMN). Subjects suffering from epilepsy showed longer MMN duration and increased amplitude in the frontal region. In this manner, MMN can be used for differential diagnosis of epilepsy.

As for psychiatric disorders, in subjects with schizophrenia typically P300 amplitude reduction and P300 latency prolongation were consistently reported (Asato et al., 1999; Chun 
et al., 2013). Patients who suffer chronically from schizophrenia exhibit reduction of P300 amplitude which is at about one standard deviation in comparison to healthy subjects (Javitt et al., 2009). Similar changes in P300 latency and amplitude has been also reported in patients with bipolar disorder (O'Donnell et al., 2004).

ERPs abnormalities associated with depression involve mainly significantly prolonged P300 latency and reduced P300 amplitude when compared with healthy individuals (Singh et al. 2000; Karagoz et al. 2005). It was described that the P300 latency correlated positively with age of the subject and severity of depression, on the contrary the amplitude of P300 correlated negatively with age (Singh et al., 2000). Further changes concerned N2, however findings were quite controversial. For example Sandman et al. (1992) described increase in N2 amplitude, on the other hand Kayser et al. (2003) reported no differences.

Other psychiatric disorders associated with changes in ERPs involved patients with social phobia who showed reductions in N1, N2 and P300 amplitudes and longer P300 latencies (Sachs et al., 2004). Subjects suffering from specific phobias (spiders, snakes) had greater amplitudes of P300 after presentation of feared stimuli (Miltner et al., 2005), chronic alcoholics had frequently (but not always) smaller P300 than healthy subjects (Pfefferbaum et al., 1991), and furthermore it has been consistently observed that alcohol induces attenuation of N1 and P2 amplitudes (Sur \& Sinha, 2009). ERPs of patients with obsessive-compulsive disorder have shown shorter P300 duration compared to normal controls (Kivircik et al., 2003) and subjects with generalized anxiety disorder had lower P300 amplitudes compared to healthy individuals (Gordeev et al., 2013). Karl et al. (2006) also summarized in their metaanalytic review ERPs changes during posttraumatic stress disorder (PTSD). There was evidence of reduced P50 suppression and also increased P300 amplitudes to trauma-related distractors and target stimuli in the context of trauma-related distractors. Moreover, subjects suffering from PTSD showed reduced P300 amplitudes and latencies to neutral target stimuli.

ERPs represent also useful tool for differentiating of various diseases. For example Hanatani et al. (2005) tried to evaluate the neurophysiological differences between panic disorder (PD) and generalized anxiety disorder (GAD). They found that the mean latencies of $\mathrm{P} 2$, N2, and P3 were shorter in the PD patients when compared to GAD and control subjects (Hanatani et al., 2005). Similarly, bipolar disorder and schizophrenia were distinguished in a study reported by O'Donnell et al. (2004) where N100, P200 and N200 amplitudes were reduced in schizophrenia patients which were not observed in patients with bipolar disorder.

\section{THE USE OF ERPS IN EXPERIMENTAL PSYCHOLOGY}

Introduction of ERPs technique also provides a unique and profitable tool for experimental psychology and related sciences. Typical examples are experimental papers concerning emotions, attention, cognitive processes and finally personality traits. Also in research of emotions ERPs are frequently used to study emotional responses to positive and negative stimuli (Moser et al., 2009; Schafer et al., 2010; Xue et al., 2013), emotional memory (Dolcos \& Cabeza, 2002), effects of emotional content on declarative memory (Gasbarri et al., 2006), emotion regulation (Hajcak et al., 2010) or emotion processing (Pollak et al., 1997).

Recordings of ERPs from normal subjects have played an increasingly important role in the study of attention (Luck et al., 2000). For example, Neuhaus et al. (2010) tested in this manner attentional mechanisms of alerting and orienting. Also involvement of certain brain areas in attentional processes (Herrmann \& Knight, 2001) and effects of aging on ERPs signs of attentional selection were investigated (Wang et al., 2012).

In summary recent findings show that ERPs technique allows to measure brain activity reflecting various cognitive processes affected by aging (Friedman 2003), modulation of cognitive processing by emotional contents (Delplanque et al., 2004) or to study ERPs

abnormalities in subjects with social phobia (Sachs et al., 2004). Other findings show that ERPs are also very convenient for study of memory. For instance, Rugg and Curran (2007) 
used ERPs technique for a study concerning recognition memory, visual working memory was tested by Drew et al. (2006) and long-term memory by Joyce and Kutas (2005).

In addition recent data show that ERPs can be used for investigation of various personality traits such as introversion/extraversion (Bartussek et al., 1996; Guerra et al., 2001), impulsivity (Shen et al. 2014), alexithymia (Franz et al., 2004; Walker et al., 2011), neuroticism (Ding et al., 2007) or antisocial personality traits (Pfabigan et al., 2012).

\section{CONCLUSION}

ERPs became widespread since 1960s of the last century in the field of neurology and psychiatry. Nowadays it represents a useful instrument for these disciplines with great potential to provide new insights into the research of human brain processes in experimental psychology.

\section{REFERENCES}

Ally, B.A., Jones, G.E., Cole, J.A., \& Budson, A.E. (2006). The P300 component in patients with Alzheimer's disease and their biological children.Biological Psychology, 72, 180 - 187.

Asato, N., Hirayasu, Y., Hiramatsu, K., \& Ohta, H. (1999). ERPs changes during neuroleptic treatment in schizophrenia-a vulnerability marker in schizophrenia. Seishin Shinkeigaku Zasshi, 101, 254 - 276.

Banerjee, N., Sinha, V.K., Jayaswal, M., \& Desarkar, P. (2014). Bereitschaftspotential in remittedpaediatricbipolardisorder. Neuroscience Letters, 568, 35 - 38.

Bares, M. (2011). Cognitive evoked potentials. Ceska a Slovenska Neurologie a Neurochirurgie, 5, 508 - 517.

Bartussek, D., Becker, G., Diedrich, O., Naumann, E., \& Maier, S. (1996). Extraversion, neuroticism, end event-related brain potentials in response to emotional stimuli. Personality and Individual Differences, 20,301-312.

Blackwood, D. H., \& Muir, W. J. (1990). Cognitive brain potentials and their application. The British Journal of Psychiatry, 157, $96-101$.

Casey, D.A. (2010). Event-related potentials and the diagnosis of Alzheimer's disease-The COGNISIONTM System. US Neurology, 6, $34-36$.

Chun, J., Karam, Z.N., Marzinzik, F., Kamali, M., O'Donnell, L., Tso, I.F., Manschreck, T.C., McInnis, M., \& Deldin, P.J. (2013). Can P300 distinguish among schizophrenia, schizoaffective and bipolar I disorders? An ERP study of response inhibition. Schizophrenia Research, 151, 175 - 184.

Ding, N., Ding, J., \& Guo, D. (2007). An event-related potential study of neuroticism influences on emotional processing. Acta Psychologica Sinica, 39, 629 - 637.

Dolcos, F., \& Cabeza, R. (2002). Event-related potentials of emotional memory: Encoding pleasant, unpleasant, and neutral pictures. Cognitive, Affective, E Behavioral Neuroscience, 2, 252 - 263.

Drew, T.W., McCollough, A.W., \& Vogel, E.K.(2006). Event-related potential measures of visual working memory.Clinical EEG and Neuroscience, 37, 286-91.

Franz, M., Schaefer, R., Schneider, C., Sitte, W., \& Bachor, J. (2004). Visual event-related potentials in subjects with alexithymia: modified processing of emotional aversive information? American Journal of Psychiatry, 161, $728-735$.

Friedman, D. (2003). Cognition and aging: A highly selective overview of event-related potential (ERP) data. Journal of Clinical and Experimental Neuropsychology, 25, $702-720$.

Garrido-Vásquez, P., Pell, M.D., Paulmann, S., Strecker, K., Schwarz, J., \& Kotz, S.A. (2013). An ERP study of vocal emotion processing in asymmetric Parkinson's disease. Social Cognitive and Affective Neuroscience, 8, 918 - 927.

Gaudreault, P.O., Gagnon, J.F., Montplaisir, J., Vendette, M., Postuma, R.B., Gagnon, K., \& Gosselin, N. (2013). Abnormal occipital event-related potentials in Parkinson's disease withconcomitant REM sleep behavior disorder. Parkinsonism and Related Disorders, 19, 212 - 217.

Gasbarri, A., Arnone, B., Pompili, A., Marchetti, A., Pacitti, F., Calil, S.S., Pacitti, C., Tavares, M.C., \& Tomaz, C. (2006). Sex-related lateralized effect of emotional content on declarative memory: An event related potential study. Behavioural Brain Research, 168, 177 - 184. 
Gordeev, S.A., Posokhov, S.I., Kovrov, G.V., \& Katenko, S.V. (2013). Psychophysiological characteristics of panic disorder and generalized anxiety disorder. Zhurnal nevrologii i psikhiatrii imeni S.S. Korsakova, 113, 11-14.

Green, J., Woodard, J.L., Sirockman, B.E., Zakers, G.O., Maier, C.L., Green, R.C., \& Watts, R.L. (1996). Event-related potential P3 change in mild Parkinson's disease. Movement Disorders, 11, 32 - 42.

Gurrera, R.J., O'Donnell, B.F., Nestor, P.G., Gainski, J., \& McCarley, R.W. (2001). The P3 auditory eventrelated brain potential indexes major personality traits. Biological Psychiatry, 49, 922 - 929.

Hajcak, G., MacNamara, A., \& Olvet, D.M. (2010). Event-related potentials, emotion, and emotion regulation: An integrative review. Developmental Neuropsychology, 35, 129 - 155.

Hanatani, T., Sumi, N., Taguchi, S., Fujimoto, O., Nan-No, H., \& Takeda, M. (2005). Event-related potentials in panic disorder and generalized anxiety disorder. Psychiatry and Clinical Neurosciences, $59,83-88$.

Fumuro, T., Matsuhashi, M., Mitsueda, T., Inouchi, M., Hitomi, T., Nakagawa, T., Matsumoto, R., Kawamata, J., Inoue, H., Mima, T., Takahashi, R., \& Ikeda A. (2013). Bereitschaftspotential augmentation by neuro-feedback training in Parkinson's disease. Clinical Neurophysiology, 124, 1398 $-1405$.

Garrido, M.I., Kilner, J.M., Stephan, K.E., \& Friston, K.J. (2009). The mismatch negativity: A review of underlying mechanisms. Clinical Neurophysiology, 120, $453-463$.

Gesualdi, A.R., \& Franca, A.I. (2011). Event-related brain potentials (ERP): an overview. Revista Linguistica, 7, $24-43$.

Herrmann, C.S., \& Knight, R.T (2001). Mechanisms of human attention: event-related potentials and oscillations. Neuroscience \& Biobehavioral Reviews, 25, 465 - 476.

Hruby, T., \& Marsalek, P. (2003). Event-related potentials- the P3 wave. Acta Neurobiologiae Experimentalis, 63, $55-63$.

Javitt, D.C., Spencer, K.M., Thaker, G.K., Winterer, G., \& Hajos, M. (2008). Neurophysiological biomarkers for drug development in schizophrenia. Nature Reviews Drug Discovery, 7, 68 - 83.

Joyce, C.A., \& Kutas, M. (2005). Event-related potential correlates of long-term memory for briefly presented faces. Journal of Cognitive Neuroscience, 17, 757 - 767.

Kaga, Y., Kanemura, H., Ishii, S., Kaga, S., \& Aihara, M. (2013). Event-related potentials for cognitive assessment of patients with epilepsy.Pediatrics $\mathcal{E}$ Therapeutics, 3, 161, doi:10.4172/2161-0665.1000161.

Karagoz, M., Alkac, U.I., Ergen, N., Eradamlar, N., \& Alpkan, L. (2005).Event-related potentials in major depression.Dusunen Adam: The Journal of Psychiatry and Neurological Sciences, 18, 180 - 186.

Karl, A., Malta, L.S., \& Maercker, A. (2006). Meta-analytic review of event-related potential studies in post-traumatic stress disorder.Biological Psychology, 71, $123-147$.

Katada, E., Sato, K., Ojika, K., \& Ueda, R. (2004).Cognitive event-related potentials: Useful clinical information in Alzheimer's disease. Current Alzheimer Research, 1, 63 - 69.

Kayser, J., Bruder, G. E., Tenke, C. E., Stewart, J. W., \& Quitkin, F. M. (2000). Event-related potentials (ERPs) to hemifield presentations of emotional stimuli: Differences between depressed patients and healthy adults in P3 amplitude and asymmetry. International Journal of Psychophysiology, 36, 211-236.

Kivircik, B.B., Yener, G.G., Alptekin, K., \& Aydin, H. (2003). Event-related potentials and neuropsychological tests in obsessive-compulsive disorder. Progress in Neuro-Psychopharmacology $\mathcal{E}$ Biological Psychiatry, 27, $601-606$.

Kuperberg, G.R. (2008). Electroencephalography, event-related potentials, and magnetoencephalography. In: D.D. Dougherty, S.L. Rauch \& J.F. Rosenbaum (Eds.) Essentials of Neuroimaging for Clinical Practice. pp.117 - 127, Arlington: American Psychiatric Publishing, Inc.

Lai, C.L., Lin, R.T., Liou, L.M., \& Liu, C.K. (2010).The role of event-related potentials in cognitive decline in Alzheimer's disease. Clinical Neurophysiology, 121, 194 - 199.

Luck, S.J., Woodman, G.F., \& Vogel, E.K. (2000). Event-related potential studies of attention. Trends in Cognitive Sciences, 4, $432-440$.

Miltner, W.H.R., Trippe, R.H., Krieschel, S., Gutberlet, I., Hecht, H., \& Weiss, T. (2005). Event-related brain potentials and affective responses to threat in spider/snake-phobic and non-phobic subjects. International Journal of Psychophysiology, 57, 43 - 52.

Moser, J.S., Krompinger, J.W., Dietz, J., \& Simons, R.F. (2009).Electrophysiological correlates of decreasing and increasing emotional responses to unpleasant pictures. Psychophysiology, 46, 17 - 27.

Naatanen, R., \& Kreegipuu, K. (2012).The Mismatch Negativity (MMN). In: S.J. Luck \& E.S. Kappenman (Eds.) The Oxford Handbook of Even-related Potentials. pp. 143 - 158, Oxford University Press, Inc.

O’Donnell, B.F., Vohs, J.L., Hetrick, W.P, Carroll, C.A.,\&Shekhar, A. (2004). Auditory event-related potential abnormalities in bipolar disorder and schizophrenia, International Journal of Psychophysiology, 53, $45-55$. 
Pedroso, R.V., Fraga F.J., Corazza, D.I., Andreatto, C.A., Coelho, F.G., Costa, J.L., \& Santos-Galduroz, R.F. (2012). P300 latency and amplitude in Alzheimer's disease: a systematic review. Brazilian Journal of Otorhinolaryngology, 78, $126-132$.

Pfabigan, D.M., Alexopoulos, J., \& Sailer, U. (2012). Exploring the effects of antisocial personality traits on brain potentials during face processing. Plos One, 7, e50283.

Pfefferbaum, A., Ford, J.M., White, P.M., \& Mathalon, D. (1991). Event-related potentials in alcoholic men: P3 amplitude reflects family history but not alcohol consumption. Alcoholism: Clinical and Experimental Research, 15, 839 - 850.

Picton, T.W. (1992). The P300 Wave of the human event-related potential. Journal of Clinical Neurophysiology, 9, $456-479$.

Picton, T.W., Bentin, S., Berg, P., Donchin, E., Hillyard, S.A., Johnson, Jr., R., Miller, G.A., Ritter, W., Ruchkin, D.S., Rugg, M.D., \& Taylor, M.J. (2000). Guidelines for using human event-related potentials to study cognition: Recording standards and publication criteria. Psychophysiology, 37, 127-152.

Pollak, S.D., Cicchetti, D., Klorman, R., \& Brumaghim, J.T. (1997). Cognitive brain event-related potentials and emotion processing in maltreated children. Child Development, 68, 773 - 787.

Rugg, M.D., \& Curran, T. (2007). Event-related potentials and recognition memory. Trends in Cognitive Sciences, 11, 251-257.

Sachs, G., Anderer, P., Margreiter, N., Semlitsch, H., Saletu, B., \& Katschnig, H. (2004). P300 eventrelated potentials and cognitive function in social phobia. Psychiatry Research, 131, $249-261$.

Sandman, C. A., Vigor-Zierk, C. S., Isenhart, R., Wu, J., \& Zetin, M. (1992). Cardiovascular phase relationships to the cortical event-related potentials of schizophrenic, depresed and normal subjects. Biological Psychiatry, 32, $778-789$.

Schafer, A., Scharmuller, W., Leutgeb, V. Kochel, A., \& Schienle, A. (2010). Are blood-injection-injury stimuli different from other negative categories? An ERP study. Neuroscience Letters, 478, 171 - 174.

Shen, I.H., Lee, D.S., \& Chen, C.L.(2014). The role of trait impulsivity in response inhibition: Eventrelated potentials in a stop-signal task. International Journal of Psychophysiology, 91, $80-87$.

Singh, R., Shukla, R., Dalal, P.K., Sinha, P.K., \& Trived, J.K. (2000). P 300 event related potential in depression. Indian Journal of Psychiatry, 42, $402-409$.

Sur, S., \& Sinha, V.K. (2009). Event-related potential: An overview. Industrial Psychiatry Journal, 18, 7073.

Tanaka, H., Koenig, T., Pascual-Marqui, R.D., Hirata, K., Kochi, K., \& Lehmann, D. (2000). Event-related potential and EEG measures in Parkinson's disease without and with dementia.Dementia and Geriatric Cognitive Disorders, 11, 39 - 45.

Vecchio, F. \& Maatta, S., (2011).The use of auditory event-related potentials in Alzheimer's disease diagnosis. International Journal of Alzheimer's disease, 2011, 653173.

Walker, S., O'Connor, D.B., \& Schaefer, A. (2011). Brain potentials to emotional pictures are modulated by alexithymia during emotion regulation. Cognitive, Affective, E Behavioral Neuroscience, 11, 463 475.

Walter, W.G., Aldridge, V.J., Cooper, R., McCallum, W.C., \& Cohen, J. (1964a). L'origineet la signification de l'onded'expectative. Revue neurologique, 111, 257 - 273.

Walter, W.G., Cooper, R., Aldridge, V.J., McCallum, W.C., \& Winter, A.L. (1964b). Contingent negativevariation: an electric sign of sensori-motor associationand expectancy in the human brain. Nature (Lond.), 203, 380 - 384.

Walter, W.G., Cooper, R., Crow, H.J., McCallum, W.C., Warren, W.J., Aldridge, V.J., van Leeuwen, W.S., \& Kamp, A. (1967). Contigent negative variation and evoked responses recorded by radio-telemetry in free-ranging subjects. Electroencephalography and Clinical Neurophysiology, 23, 197 - 206.

Wang, Y., Fub, S., Greenwood, C., Luod, Y., \& Parasuraman, R. (2012). Perceptual load, voluntary attention, and aging: An event-related potential study. International Journal of Psychophysiology, 84, 17 -25 .

Woodman, G.F. (2010). A Brief Introduction to the use of event-related potentials (ERPs) in studies of perception and attention. Attention, Perception, E Psychophysics, 72, 2031- 2046.

Xue, S., Cui, J., Wang, K., Zhang, S., Qiu, J., \& Luo, Y. (2013). Positive emotion modulates cognitive control: An event-related potentials study. Scandinavian Journal of Psychology, 54, 82 - 88. 